\title{
The Antioxidant Activity from Hydroquinone Derivatives by the Synthesis of Cinnamomium Verum J.Presl Bark's Extracted
}

\author{
Uthumporn Kankeaw and Ekkalak Masong
}

\begin{abstract}
Hydroquinone is polyphenol compound which was used as antioxidant. In this study, the hydroquinone was synthesized via aldol condensation between 1,4-cyclohexanedione and cinnamaldehyde which was extracted from the bark of Cinnamomum verum J.Presl by stream distillation and using $\mathrm{LiCl}$ as a catalyst in pyridine. The hydroquinone derivatives showed the dark brown crystal with Rf 0.50 (hexane : ethyl acetate : methanol $5: 4: 1$ ). These products were characterized by FT-IR spectroscopy which showed spectrum at $3300-3500 \mathrm{~cm}^{-1}$ (O-H stretching), 3025 cm-1 (C-H stretching of aromatic), $1660 \mathrm{~cm}^{-1}(\mathrm{C}=\mathrm{C}$ stretching of alkene) and 1450, $1502 \mathrm{~cm}^{-1}(\mathrm{C}=\mathrm{C}$ stretching of aromatic $)$, respectively. The characterization by ${ }^{1} \mathrm{H}-\mathrm{NMR}$ spectroscopy expressed ${ }^{1} \mathrm{H}-\mathrm{NMR} \quad(\mathrm{ppm}): 9.70(\mathrm{~d}, 2 \mathrm{H}, \mathrm{OH}), 6.35-7.56(\mathrm{~m}$, $8 \mathrm{H}$, aromatic protons) and $3.50\left(\mathrm{~d}, 2 \mathrm{H},-\mathrm{CH}_{2}-\right)$, respectively. The synthesized product was tested the antioxidant activity by using DPPH radical scavenging assay and the $\mathrm{IC}_{50}$ was done by spectrophotometric assay method compared with standard gallic acid. The antioxidant activity revealed that $\mathrm{IC}_{50}$ were 14.15 ppm.
\end{abstract}

Index Terms - Cinnamaldehyde, antioxidant, hydroquinone derivatives, Cinnamomum verum J.Presl.

\section{INTRODUCTION}

Cinnamomium Verum J.Presl is an evergreen tropical tree, belonging to the Lauraceae family [1]. Cinnamon barks is widely used as flavoring agent in foods and for various applications in medicine, anticancer, antioxidant and antibacterial properties [2]. The essential oil from bark is rich in trans-cinnamaldehyde with antimicrobial effects against animal and plant pathogens, food poisoning and spoilage bacteria and fungi [3]-[5]. Until now more than 300 volatiles were found as constituents of essential oils of cinnamon [6]. The essential oil derived from cinnamon leaves is rich in eugenol, moreover from the roots in camphor and that from the buts express a high amount of sesquiterpenes [7]. It has been established that the oils and extracts from cinnamon possess a distinct antioxidant activity, which is especially attributed to the presence of phenolic and polyphenolic substances [8]. Free radicals are generated in consequence of the metabolism of normal or pathological cells.

In the last years there has been a constantly rising interest in the antioxidative constituents of various medicinal plants, due

Manuscript received May 16, 2014; revised July 10, 2014.

Uthumporn Kankeaw is with the Maejo University, Chiang Mai, Thailand (e-mail: mooeed@hotmail.com). to their potential in controlling the levels of free radicals and the process of lipid peroxidation. This study is focused on the modification of cinnamaldehyde which was extracted from cinnamon bark to use them in foods and pharmaceutical preparations in order to replace synthetic antioxidants.

The modification of the structure to improve antioxidant activity was done by aldol condensation between 1 , 4-cyclohexanedione and cinnamaldehyde express in Fig. 1.

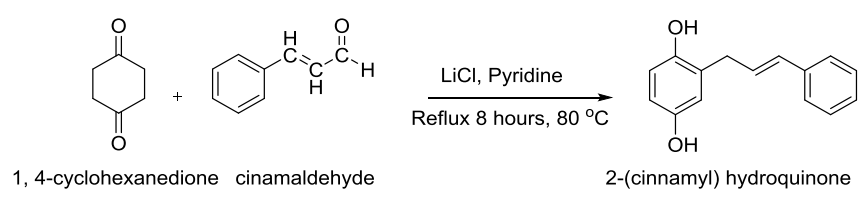

Fig. 1. Aldol condensation between 1, 4-cyclohexanedione and cinnamaldehyde.

\section{MATERIAL AND METHOD}

\section{A. Materials}

The dry bark of Cinnamomium Verum J.Presl from Sri Lanka.

\section{B. The Essential Oil Extraction}

The volatile oils of the cinnamon bark were obtain by hydrodistillation [9]. $1 \mathrm{~kg}$ of each of the cinnamon bark powders with $3 \mathrm{~L}$ of distilled water followed by heating at 100 ${ }^{\circ} \mathrm{C}$ for $8 \mathrm{~h}$. The volatile products were extracted from the water phase three times using methylene dichloride. The essential oil was characterized the structure by FT-IR spectroscopy.

\section{The Synthesis of Hydroquinone Derivative}

The synthesis strategy leading to the target compounds are illustrated in Fig. 1. The hydroquinone derivative was synthesized by $0.0065 \mathrm{~mol}$ of 1,4 -cyclohexanedione and $0.0065 \mathrm{~mol}$ of cinnamaldehyde with the presence of $\mathrm{LiCl}$ in 5 $\mathrm{mL}$ of pyridine at reflux temperature for $8 \mathrm{~h}$. The product was extract by Ethyl acetate and $10 \% \mathrm{HCl}$ and purified by column chromatography. The characterization of product was done by spectroscopic method FT-IR spectroscopy and 1H-NMR spectroscopy.

\section{Antioxidant Studies: DPPH Assay}

The method of Brand-Williams et al., [10] based on the reduction of DPPH radical solution in the presence of hydrogen donating antioxidants, was used with some modifications. One $\mathrm{ml}$ of $0.3 \mathrm{mM}$ alcoholic solution of DPPH 
was added to $2.5 \mathrm{ml}$ of the samples with different concentration of hydroquinone derivatives. The samples were kept at room temperature in the dark and after $30 \mathrm{~min}$. the optic density was measured at $518 \mathrm{~nm}$. The optic density of the samples, the control and the blank was measured in comparison with ethanol. One synthetic antioxidant, Gallic acid was used as positive control. The reaction was carried out in triplicate and the decrease in absorbance was measured at $518 \mathrm{~nm}$ after 30 minutes in dark using UV-Vis spectrophotometer. The inhibition $\%$ was calculated using the following formula.

$$
\text { Inhibition } \%=A c-A s / A c \times 100
$$

where $A c$ is the absorbance of the control and $A s$ is the absorbance of the sample.

\section{RESULTED AND DISCUSSTION}

\section{A. The Essential Oil Extraction}

The volatile oils of the cinnamon bark were obtained by hydrodistillation give the liquid yellow with unique aromatic scent (see Table I).

TABLE I: THE QUALITY OF THE VOLATILE OIL OF THE CINNAMON BARK BY HYDRODISTILLATION

\begin{tabular}{cccc}
\hline \hline & $\begin{array}{c}\text { Weight of } \\
\text { bark (kg) }\end{array}$ & $\begin{array}{c}\text { Weight of } \\
\text { volatile oil } \\
(\mathbf{g})\end{array}$ & $\begin{array}{c}\text { \% } \\
\text { yield }\end{array}$ \\
\hline 1 & 1.06 & 4.52 & 0.43 \\
.2 & 1.15 & 4.95 & 0.43 \\
3 & 1.03 & 5.40 & 0.52 \\
average & 1.08 & 4.96 & 0.46 \\
\hline \hline
\end{tabular}

The volatile oil was characteristic by IR spectroscopy compare with reference spectrum is presence in Fig. 2.

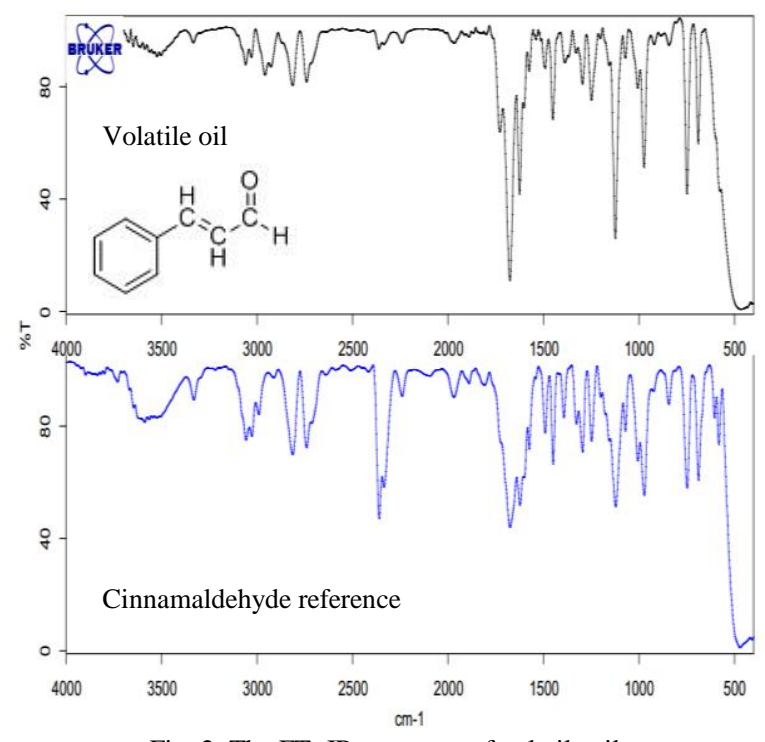

Fig. 2. The FT- IR spectrum of volatile oil.

It was found that the volatile oil is cinnamaldehyde because there are the present peak of $1676 \mathrm{~cm}^{-1}$ ( $\mathrm{C}=\mathrm{O}$ stretching), 2742, $2846 \mathrm{~cm}^{-1}$ (C-H stretching of aldehyde), $1625 \mathrm{~cm}^{-1}$ $(\mathrm{C}=\mathrm{C}$ stretching of alkene $)$ and $1450,1502 \mathrm{~cm}^{-1}(\mathrm{C}=\mathrm{C}$ stretching of aromatic), respectively. When compare the spectrum with the reference found that there's dissimilar.

\section{B. The Synthesis of Hydroquinone Derivative}

The hydroquinone derivative was done by aldol condensation between 1, 4-cyclohexanedione and cinnamaldehyde, the result show in Table II.

\begin{tabular}{lll} 
TABLE II: THE SYNTHESIS OF HYDROQUINONE DERIVATIVE \\
\hline \hline $\begin{array}{l}\text { 2-(cinnamyl) } \\
\text { hydroquinone }\end{array}$ & $\begin{array}{l}\text { melting } \\
\text { point }\left({ }^{\circ} \mathrm{C}\right)\end{array}$ \\
\hline & & \\
\hline ( hexane: ethyl acetate: methanol $(5: 4: 1)$ & \\
\hline
\end{tabular}

The hydroquinone derivative was purified by column chromatography method and the yield of product is $21.96 \%$. The mechanism of the reaction can be express in Figure 3 . In the experiment, pyridine was used as catalyst which perform as base to increase the nucleophile activity of 1 , 4-cyclohexanedione.

The synthesis product was characterized by FT-IR spectroscopy which showed spectrum at $3300-3500 \mathrm{~cm}^{-1}$ (O-H stretching), $3025 \mathrm{~cm}^{-1}$ (C-H stretching of aromatic), $1660 \mathrm{~cm}^{-1}(\mathrm{C}=\mathrm{C}$ stretching of alkene $)$ and $1450,1502 \mathrm{~cm}^{-1}$ ( $\mathrm{C}=\mathrm{C}$ stretching of aromatic), respectively. The characterization by ${ }^{1} \mathrm{H}-\mathrm{NMR}$ spectroscopy expressed ${ }^{1} \mathrm{H}-\mathrm{NMR}$ (ppm): 9.70 (d, 2H, OH), 6.35-7.56 (m, 8H, aromatic protons) and $3.50\left(\mathrm{~d}, 2 \mathrm{H},-\mathrm{CH}_{2}-\right)$, respectively. From the FT-IR spectrum, it was found that $\mathrm{C}-\mathrm{H}$ stretching of aldehyde was disappear in the other hand, $\mathrm{OH}$ stretching which is the character of hydroquinone was appeared. Moreover, the ${ }^{1} \mathrm{H}-\mathrm{NMR}$ spectrum show $2 \mathrm{H}$ of $\mathrm{CH}_{2}$ at 3.5 ppm which was connected between 1, 4 cyclohexanedione and cinnamaldehyde together. It can be concluded that the modified structure was followed by expect reaction.

\section{Antioxidant Studies: DPPH Assay}

The antioxidant activity of hydroquinone derivative is mainly due to the active of $\mathrm{OH}$ and the functional group in their structure [11]. In this study, the derivative was compare with gallic acid standard which was the hydroquinone derivative and also acts as an antioxidant and helps to protect human cells against oxidative damage [12] by DPPH free radical scavenging assay, the results are shown in Fig. 4, Fig. 5 and Table III.

A significant correlation was observed between the concentration and the scavenging of DPPH radical in the hydroquinone derivative (Fig. 5) ( $r=0.993)$ indicate that the radical scavenging capacity of each extract might be related to their concentration of the hydroquinone derivative. The results obtained from the DPPH as well as the liquid per oxidation assay employed to test the antioxidant activity of hydroquinone derivative demonstrated that the derivative give less $\mathrm{IC}_{50}$ than gallic acid but not much difference because the $\mathrm{OH}$ in the derivative is less than that reference. 


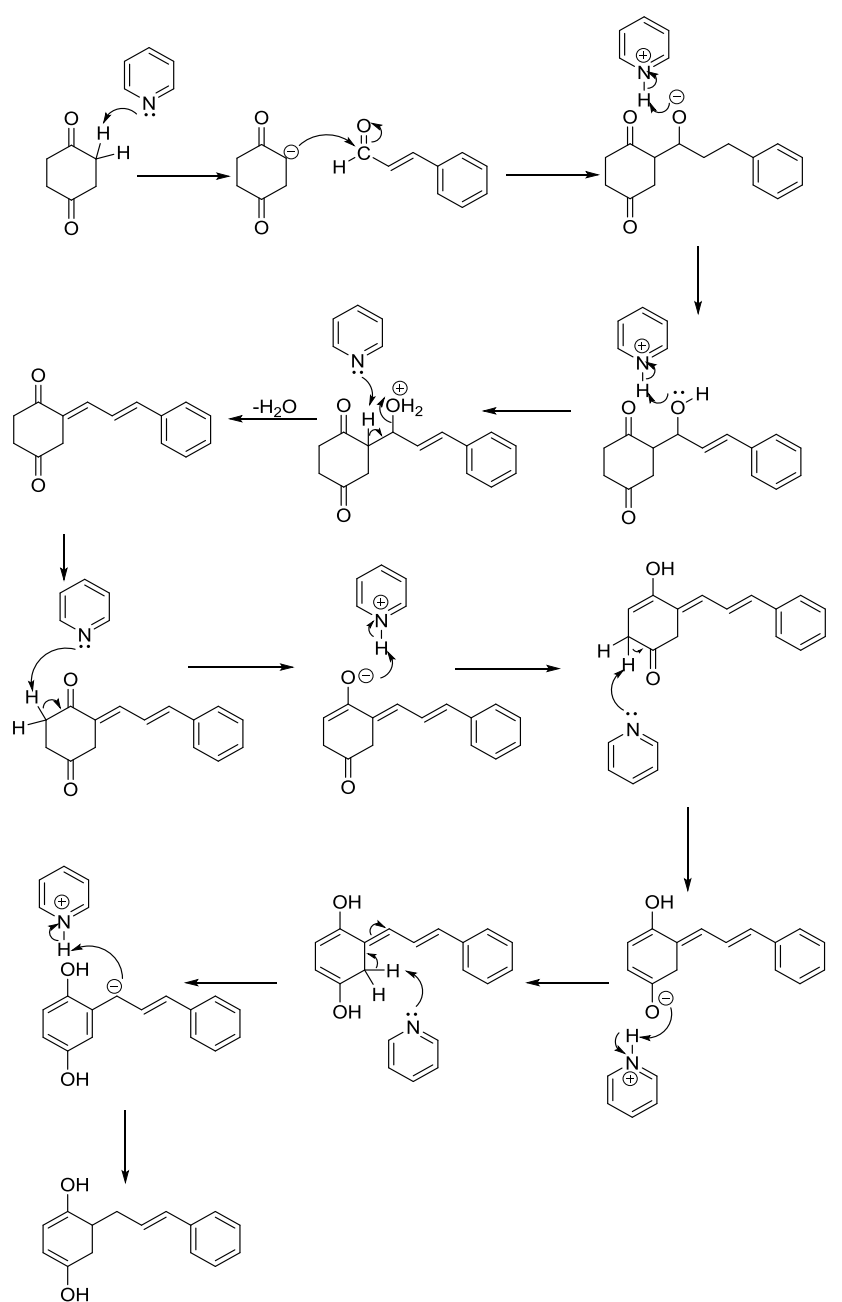

Fig. 3. The mechanism of the synthesis of hydroquinone derivative.

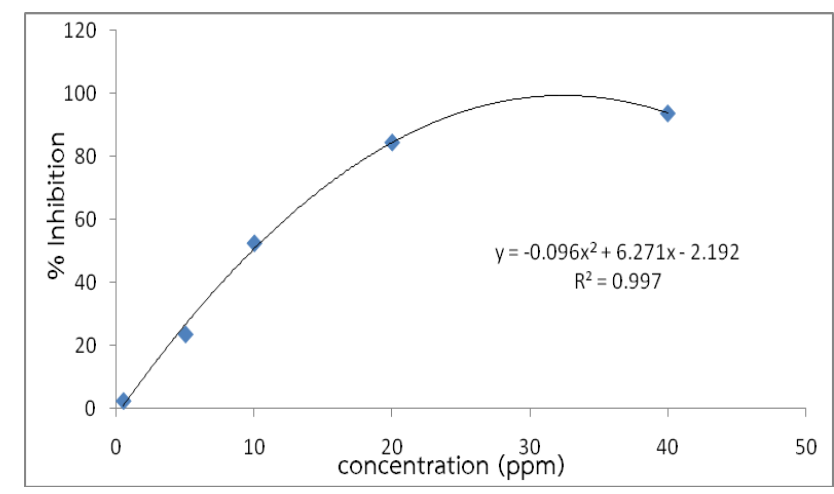

Fig. 4. Correlation between antioxidant activity and concentration of gallic acid.

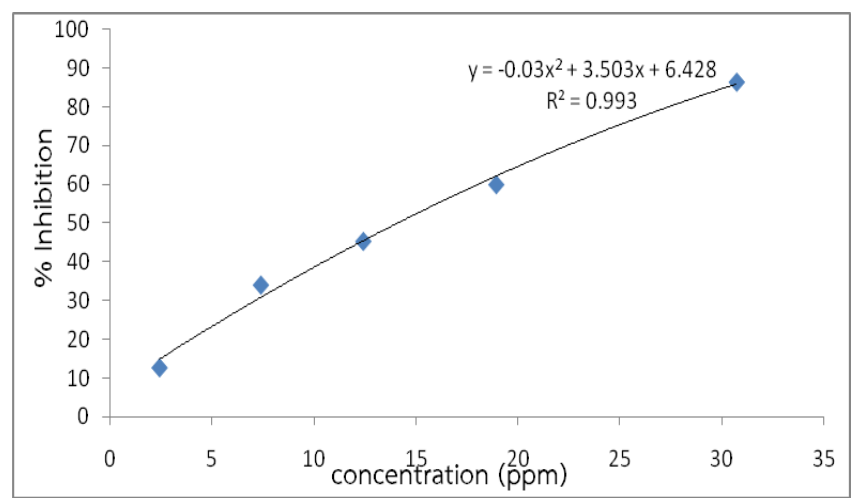

Fig. 5. Correlation between antioxidant activity and concentration of 2-(cinnamyl) hydroquinone.
TABLE III: ANTIOXIDANT ACTIVITY OF HYDROQUINONE DERIVATIVE AS DETERMINED BY DPPH FREE RADICAL SCAVENGING ASSAY

\begin{tabular}{ll}
\hline \hline & $\begin{array}{l}\mathrm{IC}_{50} \\
(\mathrm{ppm})\end{array}$ \\
\hline 2-(cinnamyl) hydroquinone & 14.15 \\
Gallic acid & 9.80 \\
\hline \hline
\end{tabular}

\section{CONCLUSION}

This present study has revealed that the antioxidant activity of hydroquinone derivative which was synthesis by the aldol condensation between 1,4-cyclohexanedione and cinnamaldehyde. This study showed the potent antioxidants and may be efficient as preventive agents in and can be seen as a potential source of useful food and drugs. Further studies have to be carried out to modification of the structure for higher antioxidant activity.

\section{ACKNOWLEDGMENT}

We are thankful to Institute of Product Quality and Standardization, Department of Chemistry, Faculty of Science, Maejo University, Maejo University for financial support and providing all necessary facilities to conduct the experiments.

\section{REFERENCES}

[1] J. Seidemannt, Cinnamon-Lauraceae, Heidelberg: Springer-Verlag, 2005, pp. 100-104.

[2] V. Katalinic, M. Milos, T. Kulisic, and M. Jukic," Screening of 70 medicinal plant extracts for antioxidant capacity and total phenols," Food Chem, vol. 94, pp. 550-557, 2004.

[3] T. Hatano, M. Takagi, and T. Yoshida, "Phenolic constituents of liquorice. VII. A new calcone with a potent radical scavenging activity and accompanying Phenols," Chem. Pharm. Bull, vol. 45, pp. 1485-1492, 1997

[4] M. Lis-Balchin, S. Deans, and E. Eaglesham, "Relationship between bioactivity and chemical composition of commercial essential oils," Flavour Fragr. J, vo1. 8, pp. 98-104, 1998.

[5] M. Mastura, M. A. N Azah, S. Khozirah, R. Mawardi, and A. A. Manaf, "Anticandidal and antidermatophytic activity of Cinnamomum species essential oils," Cytobios, vol. 98, pp. 17-23, 1999.

[6] L. Yan-Qua, K. De-Xin, and W. Hong, "Analysis and evaluation of essential oil components of cinnamon barks using GC-MS and FTIR spectroscopy," Industrial Crops and Product, vol. 41, pp. 269-278, 2013.

[7] W. Brand-William, M. Cuelier, and M. E. Berset, "Use of free radical method to evaluate antioxidant activity," Lebensm. Wiss. U. Technol, vol. 28, pp. 25-30, 1995.

[8] G. Singh, S. Maurya, M. P. Lampasona, and C. A. N. Cantalan "A comparision of chemical, antioxidant and antimicrobial studies of cinnamon leaf and bark volatile oils, oleoresins and their constituents," Food and Chemical Toxicology, vol. 45, pp. 1650-1661, 2007.

[9] L. F. Yamaguchi, H. G. Lago, T. M. Tanizaki, P. D. Mascio, and M. J. Kato, "Antioxidant activity of prenylated hydroquinone and benzoic acid derivatives from Piper crassinervium Kunth," Phytochemistry, vol. 67, pp. 1838-1843, 2006.

[10] S. Sasaki, T. Tozawa, Y. Matsushita, and T. Satoh, "Anovel diterpene para-hydroquinone compound derived from cryptoquinone protects neuronal cells against oxidative stress," Neuroscience Letters, vol. 548, pp. 132-136, 2013.

[11] H. Bagheri, M. Yazid, B. A. Manap, and Z. Solati, "Antioxidant activity of Piper nigrum $\mathrm{L}$. essential oil extracted by supercritical $\mathrm{CO}_{2}$ extraction and hydro- distillation," Talanta, vol. 121, pp. 220-228, 2014.

[12] P. M. Dewick and E. Haslam, "Phenol biosynthesis in higher plants. Gallic acid," Biochemical Journal, vol. 113, pp. 537-542, 1969. 
Uthumporn Kankeaw was born in Chiang Mai of Thailand on $3^{\text {rd }}$ December, 1977. She graduated in B.Sc. and M.Sc. of chemistry from Chiang Mai University, Ph.D degree of petrochemical from Chulalongkorn University in 1997. She is now a lecturer of organic chemistry and a researcher of organic chemistry in Maejo University.

During lecturer time, She got research fund from National Research Council of Thailand
(NRCT) to study under the topic "The synthesis of anti-fungal benzimidazole derivatives by using Desmos chinensis leaves extracted," and also got another research fund from TRF (Thailand Research Fund) for research in "The synthesis of hydroquinones antioxidants for natural rubber latex".

For this research, she is working with Ekkalak Masong, the student who studied in Maejo University moreover the research is the part of senior project. 